\title{
SISTEMAS DE ESPAÇOS LIVRES E METRÓPOLE CONTEMPORÂNEA: REFLEXÕES A PARTIR DO CASO DA REGIÃO METROPOLITANA DE CAMPINAS
}

\author{
OPEN SPACES SYSTEMS AND CONTEMPORARY METROPOLIS: REFLECTIONS FROM \\ THE CASE OF THE CAMPINAS METROPOLITAN REGION
}

Eugenio Fernandes Queiroga

Professor doutor da Faculdade de Arquitetura e Urbanismo da USP e da Faculdade de Arquitetura e Urbanismo CEATEC PUC-Campinas.

e-mail: queiroga@usp.br

Wilson Ribeiro dos Santos Jr.

Professor doutor da Faculdade de Arquitetura e Urbanismo CEATEC PUC-Campinas, com mestrado em Urbanismo (Posurb) pela mesma instituição.

e-mails: wilson@puc-campinas.edu.br; e-mail:wilsonrsj@terra.com.br

José Roberto Merlin

Professor doutor da Faculdade de Arquitetura e Urbanismo CEATEC PUC-Campinas.

e-mail: jrmerlin@uol.com.br

\section{RESUMO}

Este artigo aborda algumas considerações sobre a pertinência e a atualidade de pesquisa em curso sobre sistemas de espaços livres na metrópole brasileira contemporânea, apresentando, inicialmente, um quadro de referência relativo à inserção da região metropolitana de Campinas na conformação espacial mais geral da megalópole da região Sudeste do país, situando, a seguir, algumas questões sobre as características de urbanização dispersa e policêntrica que se observa nesse território metropolitano, identificando fluxos e vetores de expansão. Discute a utilização dos novos instrumentos de intervenção à disposição do planejamento urbano, como - Estatuto da Cidade, focando a necessária atualização dos mesmos para o equacionamento das demandas atuais do ponto de vista da construção da qualidade do espaço urbano e da esfera de vida pública.

Palavras-chave: Sistemas de espaços livres, requalificação urbana, novas territorialidades, legislação urbanística, região metropolitana de Campinas.

\begin{abstract}
This article discourses on the relevancy and the present time of research on systems of open spaces in the brazilian metropolis contemporary. Initially discourses on the region metropolitan of Campinas as integrant territory of the Southeastern megalopolis of Brazil. To follow some questions are placed on the characteristics of dispersed and many nucleus urbanization that if observes in this metropolitan territory. To flows and vectors of expansion identify themselves. It is argued use of the new instruments of intervention to the disposal of the urban planning, as the Statute of the City. It is emphasized necessary update of such instruments for the satisfaction of the referring current demands to the quality of the urban space and the sphere of public life.
\end{abstract}

Key words: Open spaces systems, urban requalification, news territorialities, urban legislation, Campinas metropolis. 


\section{1 - INTRODUÇÃO}

Este artigo registra aspectos das atividades de pesquisa desenvolvidas pelo Núcleo Campinas do Projeto Temático de Pesquisa, de caráter interinstitucional, apoiadas pela Fapesp e CNPq, intituladas Os sistemas de espaços livres e a constituição da esfera pública contemporânea no Brasil (QUAPÁ-SEL). O Núcleo Campinas está estruturado no Grupo de Pesquisa Requalificação Urbana CEATEC PUC-Campinas e conta, também, com pesquisador do Laboratório de Paisagem - LABPA-FAUUSP. Uma versão preliminar deste artigo, intitulada $O$ planejamento tradicional e os sistemas de espaços livres na metrópole contemporânea, foi apresentada no IX Encontro Nacional de Ensino de Paisagismo em Escolas de Arquitetura e Urbanismo no Brasil - IX ENEPEA -, em Curitiba.

A importância do estudo da região metropolitana de Campinas, no âmbito do referido Projeto Temático, deve-se ao fato de aquela manifestar, em seu território, de maneira muito expressiva, alguns dos mais típicos fenômenos da urbanização contemporânea, como a urbanização dispersa e fragmentada, forte segregação socioespacial, policentralidade, envolvidos por fluxos e dinâmicas "inter" e "intra" metropolitanas de grande intensidade.

O Núcleo Campinas, dada a exemplaridade da metrópole campineira e adjacências, como estudo de caso de urbanização dispersa e fragmentada, optou por elaborar cartas temáticas como instrumento de investigação das situações urbanas diversificadas e representativas que compõem esse território metropolitano, tais como as que se ve-

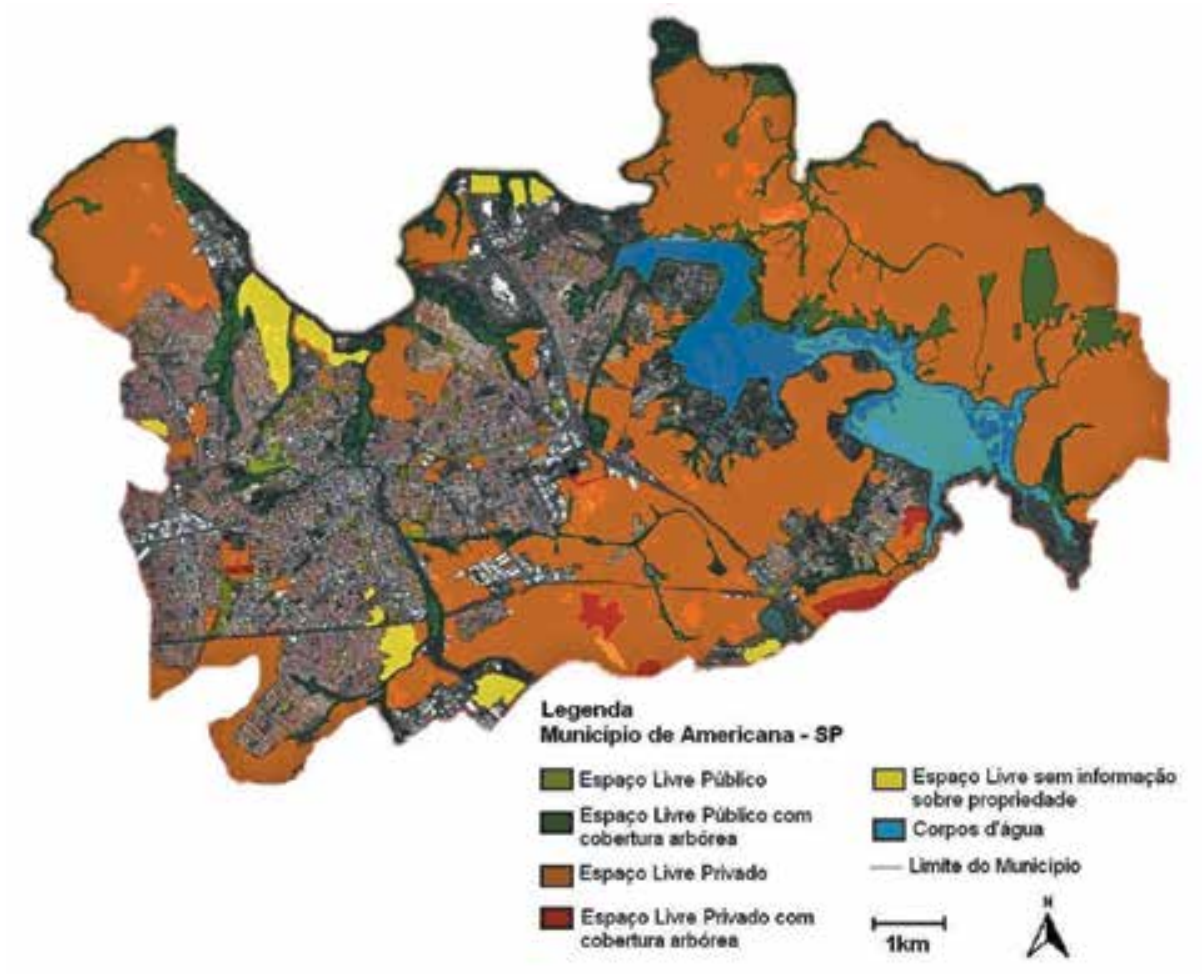

Figura 1: Levantamento geral dos espaços livres de Americana Crédito: Cauana Nandim. Iniciação Científica PIBIC PUC-Campinas, 2008 


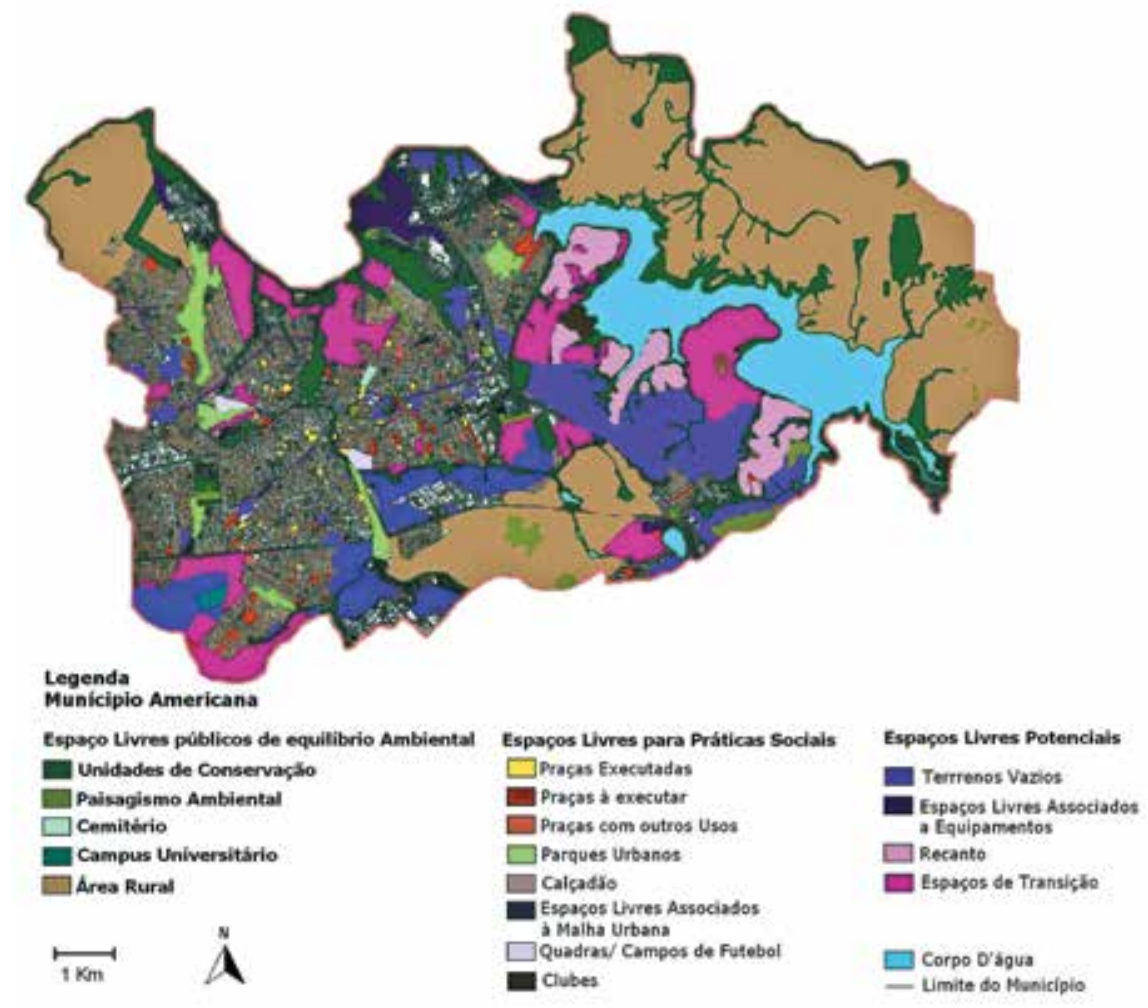

Figura 2: Levantamento geral dos espaços livres de Americana

Crédito: Cauana Nandim. Iniciação Científica PIBIC PUC-Campinas, 2008

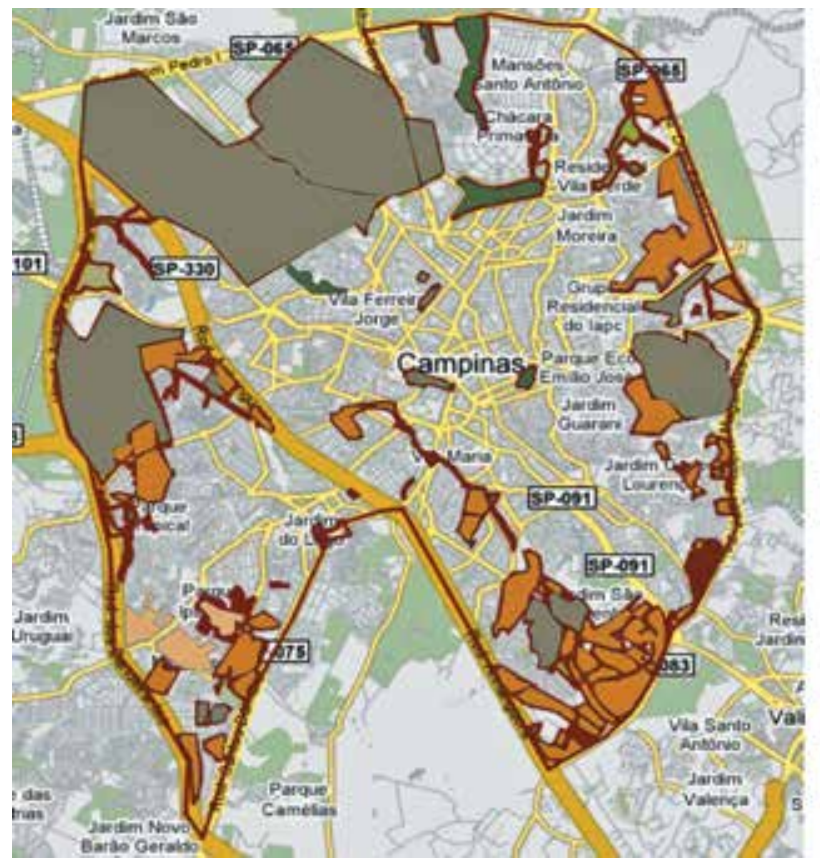

\section{Legenda}

\section{Espaço Livre Público}

Sem cobertura vegetal arborea significativa

Com cobertura vegetal arbórea significativa

\section{Espaço Livre Privado}

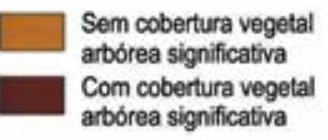

\section{Espaço Livre Sem Informaçẵo Sobre Propriedade}

Sem cobertura vegetal arbórea significativa Com cobertura vegetal arbórea significativa

Figura 3: Levantamento geral dos espaços livres da Macrozona 4 do município de Campinas Área de urbanização consolidada Crédito: Thiago G. Font. Iniciação Científica FAPIC PUC-Campinas, 2008 
rificam em determinadas áreas do núcleo central da metrópole, o município de Campinas e em municípios que apresentam portes, localizações e inserções diferenciadas no território metropolitano.

Assim, as primeiras cartas elaboradas, como as relativas aos municípios de Campinas e Americana, buscaram indicar os principais espaços livres contidos nos respectivos perímetros urbanos dos municípios estudados da região metropolitana de Campinas, quais sejam: os espaços livres públicos (bens de uso comum do povo e bens de uso especial nos quais os espaços livres possuem, no mínimo, meio hectare) e os espaços livres privados (clubes, cemitérios não-públicos, glebas não-parceladas de, no mínimo, um hectare, ou conjuntos de lotes não-ocupados equivalentes a uma quadra urbana).

Além disso, nessa primeira carta foram identificados os espaços livres com significativa cobertura arbórea e, no que tange à ação humana sobre a base hídrica, indicaram-se os reservatórios (represas e açudes) significativos para a escala de análise municipal.

A leitura prévia da paisagem e do ambiente do território metropolitano campineiro e de seu entorno realizou-se, sobretudo, pela análise da cartografia disponibilizada pelas prefeituras dos municípios, objetos de estudo da pesquisa, pela análise geral de fotos aéreas do território investigado, por visitas a campo e sobrevôos realizados na escala da metrópole e do município de Campinas.

Essa leitura ressaltou a expressiva fragmentação e dispersão urbana onde se apresentam extensas áreas de glebas não-parceladas, para fins urbanos, dentro dos respectivos perímetros urbanos municipais. Considerou-se fundamental produzir essa cartografia, pois as cartas municipais referentes aos respectivos sistemas de espaços livres apenas indicam as áreas públicas, muito menos extensas que as glebas e conjuntos de lotes ainda desocupados nos perímetros urbanos de cada município. Há, portanto, um grande estoque de espaços livres não-ocupados para fins urbanos que, se não forem tomados os devidos cuidados, em futuro não muito distante, a continuarem os atuais padrões de crescimento urbano nos quais se destacam loteamentos e condomínios fechados de baixa densidade, ter-se-á uma forte transformação na paisagem e no ambiente da metrópole campineira e de municípios adjacentes, com fortes impactos físicos (impermeabilização do solo, enchentes, ilhas de calor, entre outros) e sociais, diminuição relativa dos espaços públicos de convívio, segregação socioespacial, restrições de mobilidade urbana e outras.

Por outro lado, a presença de grandes estoques de glebas e terrenos ainda nãoocupados para fins urbanos potencializa a discussão sobre políticas públicas voltadas à requalificação de sistemas de espaços livres - públicos e privados - com repercussões seja na esfera social, como os espaços de lazer e convívio, seja nos fluxos metropolitanos, criando espaços para alternativas de menor impacto de mobilidade urbana, seja na dimensão ambiental, permitindo a formação de sistemas de espaços verdes mais integrados, com os ganhos ecológico-ambientais decorrentes (aumento da biodiversidade, constituição de microclimas mais agradáveis, drenagens pluviais mais adequadas e econômicas). 
Simultaneamente à análise da cartografia existente e à produção das novas cartas com os dados obtidos nos levantamentos, buscou-se, ainda, conhecer as legislações existentes nos vários níveis do poder público relacionadas à constituição dos sistemas de espaços livres e deteve-se na leitura e discussão da legislação urbanística e dos atuais instrumentos de gestão, com enfoque especial no Estatuto da Cidade e nos planos diretores recém-aprovados.

\section{2 - A INSERÇÃO DA REGIÃO METROPOLITANA DE CAMPINAS NA MEGALÓPOLE DO SUDESTE}

A região metropolitana de Campinas, com seu contexto territorial articulado por uma densa rede de auto-estradas, tornou-se um importante destino de localização de parte das atividades do terciário superior que migraram da região metropolitana de São Paulo. Esse processo de deslocamento espacial, acelerado nas últimas décadas, configurou um novo e extenso território continuum urbanizado, heterogêneo, complexo e polinucleado, denominado de megalópole do Sudeste do Brasil (QUEIROGA, 2008). Esse território megalopolitano se estende, grosso modo, entre o Rio de Janeiro e Ribeirão Preto, envolvendo o chamado Complexo Metropolitano Expandido (EMPLASA, 2004), mas os contornos do processo de megalopolização em curso definem uma nova entidade urbana, que inclui e transcende a noção de macrometrópole.

A megalópole do Sudeste brasileiro constitui a mais importante concentração urbanoindustrial da América Latina, com PIB maior do que o de qualquer país da América do Sul, salvo, evidentemente, o do Brasil. Do ponto de vista demográfico, a megalópole do Sudeste também se destaca nos indicadores globais. Englobando as duas mais importantes metrópoles do país, concentra uma população de cerca de 42 milhões de habitantes (Censo 2000), superior à de regiões com importante concentração demo-

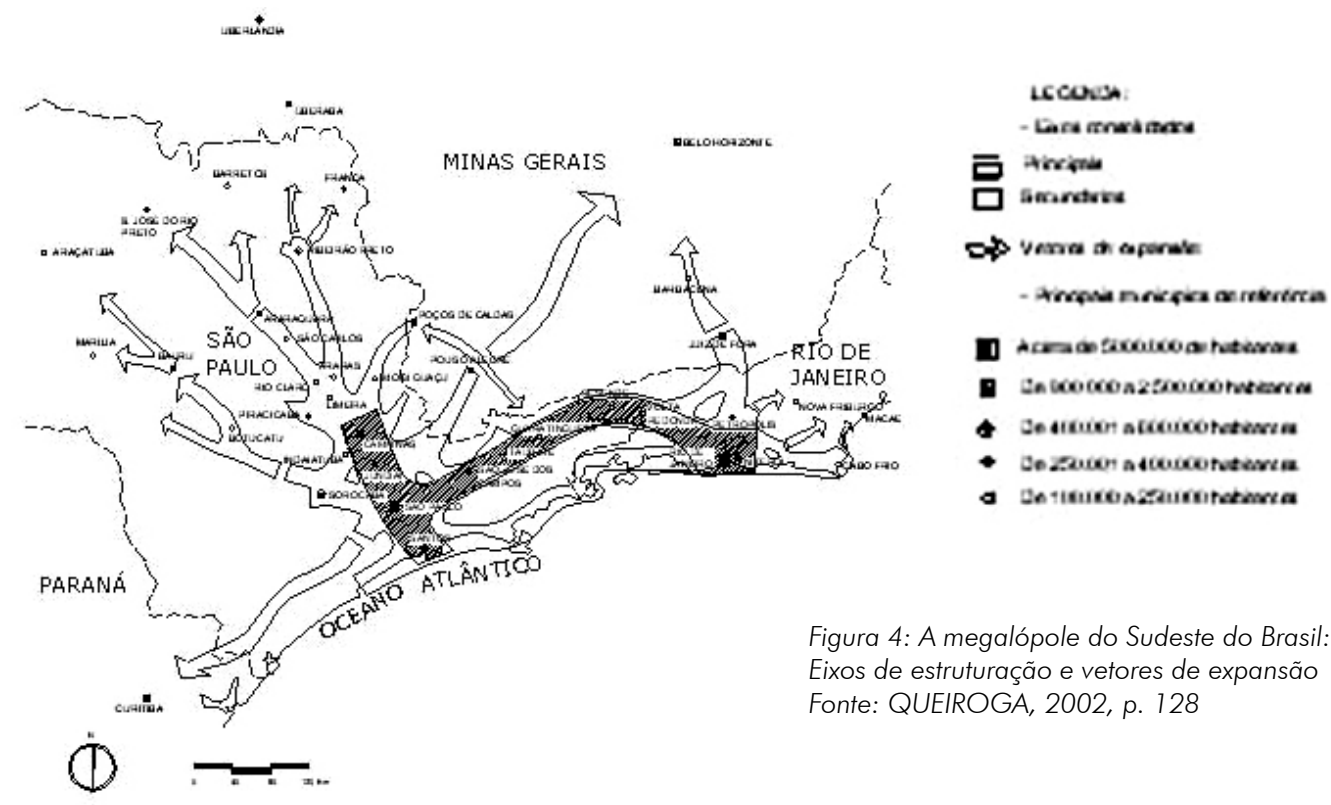


gráfica como a Califórnia, nos Estados Unidos, e, na América Latina, inferior apenas à população de países como a Colômbia, o México e o Brasil.

Em meados da década de 1970, iniciava-se forte expansão da atividade industrial para além da região metropolitana de São Paulo. Essa desconcentração industrial foi mais intensa, principalmente, em um raio de aproximadamente $150 \mathrm{~km}$ da capital, atingindo as principais regiões já historicamente mais industrializadas do estado de São Paulo: Campinas, Sorocaba, Baixada Santista e Vale do Paraíba.

Na década de 1980 consolidava-se a "macrometrópole" paulista (SOUZA, 1978) e seu território ocupava a parcela mais contínua e concentrada do processo de dispersão da indústria metropolitana, grosso modo, envolvendo as regiões administrativas de Sorocaba, Campinas, São José dos Campos e Baixada Santista, além, evidentemente, da Grande São Paulo. Nesse processo, a região metropolitana de São Paulo não perde importância, reafirmando a posição de comando - principal praça financeira e locus das sedes de grandes empresas, especialmente na articulação das relações com o mercado globalizado - embora apresente queda significativa em outros indicadores, tais como renda, emprego, etc., que aferem os níveis médios de qualidade de vida urbana e ambiental. Na macrometrópole, ao contrário da situação anterior da metrópole industrial, a "periferia" - área de produção - detinha melhores níveis médios de vida que o "centro inicial" - área de comando. Esse indicador já apontava para a formação de uma nova realidade urbana, muito além de mera expansão da metrópole industrial paulistana.

A expansão de áreas industrializadas, propiciada, entre outros motivos, pela aproximação com o maior mercado potencial de consumo do país, impulsionou o crescimento urbano, enquanto migrantes de outros estados, que se fixavam na metrópole paulistana, foram atraídos, também, para outras cidades, sobretudo Campinas, mas também São José dos Campos, Sorocaba, Santos e Ribeirão Preto. Muitos desses acabaram morando em municípios periféricos desses núcleos, configurando fortes processos de conurbação e mesmo de indução de novas áreas de metropolização.

$\bigcirc$ crescimento industrial de setores mais modernos - cada vez mais necessitando de atividades terceirizadas, tanto ligadas à produção quanto à administração e à pesquisa - e o crescimento populacional, ampliaram as atividades do terciário superior também fora da capital, desencadeando ciclo de intensificação dessa reestruturação urbano-industrial no território paulista, iniciando, inclusive, expansão seletiva para além das fronteiras do estado. Ocorreu, a partir daí, uma significativa metamorfose: de macrometrópole centrada na cidade de São Paulo passa-se a uma megalópole, onde outros centros urbanos compõem uma complexa rede relacionada ao terciário superior; destacando-se, além da capital paulista, as cidades do Rio de Janeiro, Campinas, São José dos Campos, Ribeirão Preto e Sorocaba. Estabelece-se, dessa maneira, uma nova estrutura territorial, uma nova entidade urbana: a megalópole do Sudeste do Brasil; ainda que não reconhecida oficialmente pelo Estado, é nela que se concentram, na atualidade, os maiores investimentos de capitais, sejam públicos ou privados, sejam nacionais ou estrangeiros (QUEIROGA; BENFATTI, 2007). 
Nesse processo de difusão industrial e de serviços por amplo território, a região metropolitana de Campinas foi oficialmente instituída em 2000, como resultado da consolidação de Campinas e seu entorno, desde 1980 como o segundo centro industrial do país em valor de produção (IBGE, 1984) e, posteriormente, como o principal centro do país nos setores industriais de informática e telecomunicações. Contribuíram para isso: uma ótima rede de estradas de rodagem; um aeroporto internacional com o maior movimento, em valor, de cargas do país; capacitação técnica e científica vinculada a vários centros de pesquisa estabelecidos em Campinas.

Maior pólo de uma rede urbana constituída no interior paulista com o advento da economia cafeeira do século XIX, Campinas possuía, a partir do último quartel do século XIX, o maior entroncamento ferroviário do estado de São Paulo, anterior ao da

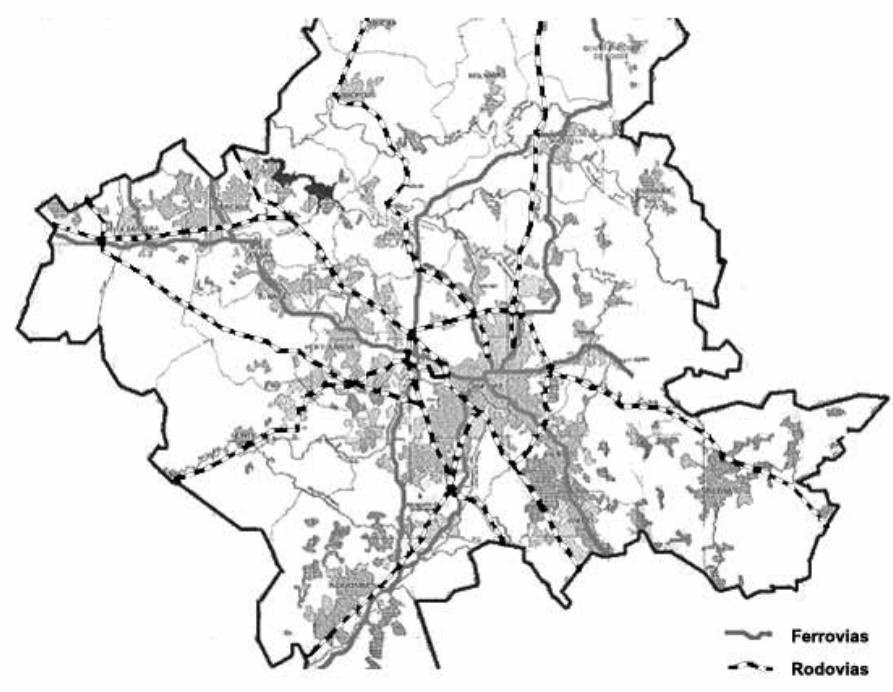

Figura 5: A urbanização da região metropolitana de Campinas e os sistemas de circulação Crédito: Desenho de QUEIROGA, 2007; base: BITTENCOURT, 2004

capital. Com o declínio do transporte ferroviário, nos anos 50, e a rápida ascensão do transporte rodoviário, Campinas passou a contar com importante sistema de rodovias, consolidando-se, novamente ali, desde os anos 80 , o segundo mais importante entroncamento de rodovias expressas de São Paulo, atrás apenas da capital. Criava-se, no território campineiro e em seu envoltório, as condições infra-estruturais, econômicas e demográficas para o estabelecimento de uma rede urbana que assumiria paulatino caráter metropolitano.

A notável difusão industrial pelo interior paulista, conjugada a um avanço tecnológico na agricultura, permitiu índices médios bastante elevados de qualidade de vida urbana.

Nos últimos dez anos, no estado de São Paulo, houve forte declínio nos postos de trabalho do setor secundário e ascensão do setor terciário. As duas maiores taxas de elevação no nível de emprego, no setor de serviços, aconteceram em municípios com renda per capita relativamente mais elevada (Campinas e Ribeirão Preto), que se constituem, há mais de século, importantes núcleos de comércio e serviços, em pólos de regiões administrativas de atividade agrícola fortemente capitalizada. 
A expansão da megalópole - função inicial da dispersão da produção industrial e do fortalecimento de núcleos de atividades do terciário superior - envolve, de forma complementar, extensas áreas voltadas ao lazer das camadas de renda média e alta.

Nesse quadro ampliado dos espaços de produção e consumo, vai se verificando a continuidade do processo de expansão territorial da megalópole ao longo dos principais eixos rodoviários que irradiam, principalmente da capital paulista, mas não só dela, estruturando uma configuração territorial mais complexa. Tal como na fase inicial (macrometropolitana), o processo não ocorre igualmente em todas as direções, mas confirma e privilegia os vetores que passam pelos principais núcleos urbanos das áreas nas quais já se vinha estabelecendo a macrometropolização paulista; articulando, também agora, no entanto, importantes municípios do sul de Minas Gerais e, muito fortemente, o Rio de Janeiro.

O centro mais forte de atividades econômicas da Megalópole do Sudeste continua sendo a região metropolitana de São Paulo, embora as taxas de crescimento (demográfico, de empregos no setor secundário ou terciário, do valor de produção, etc.) ali encontradas sejam menores que dos importantes centros urbanos da megalópole situados em seu entorno.

A região metropolitana de Campinas, inserida nesse contexto como um de seus núcleos estruturadores, apresenta-se como exemplar expressão do território megalopolitano. As auto-estradas ampliam a presença no território, cumprindo diversos papéis, do escoamento de produtos de exportação, vindos de outros estados ou ali produzidos, ao tráfego cotidiano de pessoas indo e vindo do trabalho, escolas, compras ou lazer. São verdadeiras "avenidas metropolitanas", ainda que pedagiadas e compartilhadas com fluxos e escalas de conexão diferenciadas, e, atualmente, são também infovias, capacitando o território a cumprir novos papéis produtivos, informacionais e comunicacionais. Os fluxos na metrópole campineira são intensos e ainda se realizam com grande eficiência, diferentemente do observado nas maiores metrópoles da megalópole (São Paulo e Rio de Janeiro), nas quais os congestionamentos e as deseconomias trazidas pelo aumento progressivo da frota de veículos são cada vez maiores.

Na região metropolitana de Campinas, a expansão da megalopolização acompanhou os principais eixos rodoviários ali implantados, como se segue:

- Pela rodovia Anhangüera, atingindo Araras de forma intensa e rumando, ainda de forma descontínua, até Ribeirão Preto, cuja área de influência, para alguns serviços, chega ao triângulo mineiro e mesmo sul de Goiás;

- pela rodovia Washington Luís, a megalopolização é intensa até Rio Claro, seguindo para São Carlos e Araraquara, e já impacta a estrutura urbano-industrial de São José do Rio Preto (402 mil habitantes - IBGE 2008);

- pela Rodovia Adhemar de Barros, na qual as interações urbanas são mais fortes até Mogi-Guaçu (132 mil habitantes - IBGE 2008), mas já chegando até Poços de Caldas - MG;

- pela rodovia D. Pedro I, articulando diretamente as regiões de Campinas e do 
Vale do Paraíba, e daí ao litoral norte de São Paulo, ou rodovia Presidente Dutra ao Rio de Janeiro;

- pela rodovia Santos Dumont, com interações urbanas muito fortes até Sorocaba, formando uma intensa conurbação funcional; observa-se, pelas imagens de satélite do início deste século, uma urbanização mais intensa entre Campinas e Sorocaba do que entre Sorocaba e São Paulo, denotando o vigor da dinâmica imobiliária desse eixo megalopolitano (Campinas-Sorocaba); Sorocaba, por sua vez, conurbada fisicamente com municípios vizinhos, configura-se como uma metrópole de fato e, a partir desse vetor, a expansão megalopolitana ocorre pelo eixo da rodovia Castelo Branco, atingindo Tatuí (101 mil habitantes - IBGE 2008), Botucatu (120 mil habitantes - IBGE 2008), impactando, ainda de forma menos sensível na paisagem, até Bauru (347 mil habitantes - IBGE 2008).

Cabe ressaltar, no entanto, que, apesar da impressionante rede rodoviária instalada, a fluidez da região metropolitana de Campinas é bastante seletiva, apresentando custos e distâncias de deslocamento proibitivos aos mais pobres, e o território fragmentado, segregado e pouco denso da metrópole de Campinas se coloca como mais um obstáculo ao pleno exercício da cidadania de significativa parcela de seus habitantes (QUEIROGA; BENFATTI, 2007).

Novamente, nesse aspecto, a região metropolitana de Campinas exemplifica as dinâmicas socioespaciais que se apresentam na construção do território megalopolitano. A fragmentação das manchas urbanas, decorrente de perversos processos especulativos e de uma produção imobiliária, nos quais os interesses privados dos empreendedores se sobrepõem, em muito, aos interesses públicos, é das mais gritantes entre as metrópoles brasileiras. A conexão entre os novos tecidos urbanos acontece, via de regra, de forma indireta, por estradas e avenidas e não por continuidade das malhas viárias, gerando, em grande parte, espaços fechados, de acesso controlado, sejam aqueles destinados à moradia (condomínios ou loteamentos fechados), sejam ao trabalho (centros empresariais, centros de pesquisa, condomínios industriais) ao consumo-lazer (hipermercados, parques temáticos e shopping centers), ao estudo (escolas particulares e universidades com campi bastante afastados) ou mesmo à saúde (hospitais universitários em campi distantes, hospitais de referência internacional próximos aos primeiros e distantes da maioria da população). Enfim, para os possuidores de renda alta e vários automóveis não é difícil usufruir a metrópole de Campinas, porém não se pode dizer o mesmo da população mais carente que depende do transporte coletivo.

\section{3 - POTENCIALIDADES E CONFLITOS NA LEGISLAÇÃO URBANÍSTICA: UMA DISCUSSÃO ATUAL}

\section{1 - A dimensão metropolitana: novos parâmetros de intervenção}

A emergência da dimensão metropolitana vem gerando, nas últimas décadas, a necessidade urgente de construção de novos instrumentos de gestão e elaboração de políticas públicas afinadas com essa escala de intervenção no território. As formas tra- 
dicionais de atuação do Estado, baseadas em marcos federativos ultrapassados e em processos de planejamento urbano controladores e predeterminados, não conseguem responder aos dilemas e desafios propostos por essa dinâmica e atual dimensão das aglomerações urbanas.

O entendimento de o espaço metropolitano não se constituir em espaço homogêneo e linear, e sim em rede de geometria variável articulada por pontos fortes de centralidade (PORTAS,1992), passível de ser disciplinado e organizado a partir de linhas invariantes, cede, progressivamente, espaço para novas abordagens de compreensão da dinâmica e escala dos fluxos e relações que se estabelecem nas aglomerações metropolitanas.

As regiões metropolitanas se tornaram o locus principal da mudança, da possível transformação da realidade social. Concentram o capital financeiro e produtivo, o conhecimento e o poder político, constituindo-se como elementos de articulação da região sob sua influência com a economia global.

Para a elaboração e implementação de políticas públicas de grande impacto, é necessário entender as regiões metropolitanas não a partir de seu espectro administrativo com a tradicional divisão nas esferas dos poderes municipais, estaduais e federais, mas como grandes vetores de integração espacial, articulados pela rede de transportes e pelos fluxos de conexão intrametropolitanos, interligando as atividades significativas distribuídas espacialmente pelo território metropolitano (SANTOS JR, 2006).

O enfrentamento dos problemas observados nas grandes cidades ou regiões metropolitanas, por suas dimensões e complexidades, como o tratamento adequado dos sistemas de espaços livres, a decadência de áreas centrais, o crescimento desordenado das periferias urbanas, a obsolescência de setores industriais, a permanência de tecidos urbanos residuais, a deterioração dos recursos e condições ambientais que extrapolam os limites dos municípios coloca, na ordem do dia, a utilização de novos instrumentos de legislação urbanística e estratégias eficazes a articularem diretrizes conjuntas de intervenção de caráter local com ações integradas de caráter regional ou intrametropolitano.

As diversas experiências recentes baseadas em novos parâmetros de intervenção e gestão do território urbanos, voltadas para a reversão do crescimento descontínuo e explosivo das periferias urbanas, com a reocupação das áreas centrais, as reconversões de uso de setores urbanos em decadência e a incorporação das questões ambientais na agenda das cidades constituem importantes referências na busca de novas perspectivas para o planejamento urbano e regional.

Nessas experiências urbanísticas, a revisão do planejamento tradicional passou a priorizar, para além dos planos e legislações existentes, a montagem das condições de viabilidade de programas de intervenção, a busca de acordos progressivos entre os interlocutores da cena urbana, o aproveitamento de oportunidades e a verificação e acompanhamento dos impactos decorrentes.

Algumas estratégias de intervenção urbana em curso nos municípios da região metropolitana de Campinas, inclusive aquelas com potencial intrametropolitano, como 
as da área de transporte e abastecimento de água, entre outras, implicam para sua efetivação no equacionamento dessas novas escalas de atuação do poder público, no estabelecimento de parcerias com a iniciativa privada, a partir da adoção de planos abrangentes que integrem as diretrizes aprovadas no âmbito dos planos diretores recém-aprovados, com políticas integradas e metropolitanas de desenvolvimento socioeconômico e urbano.

É nesse contexto que interessa analisar os conflitos da legislação urbanística atual e as potencialidades dos novos instrumentos criados no bojo do Estatuto da Cidade, bem como os novos planos diretores com caráter participativo.

\section{2 - O Estatuto da Cidade: algumas reflexões necessárias}

A produção das cartas temáticas relacionadas aos sistemas de espaços livres, elaboradas pelo Núcleo Campinas basearam-se, em boa medida, nos dados e material cartográfico disponível nos recém-aprovados planos diretores municipais e, ao analisálos, entendemos ser extremamente necessário contextualizar as dinâmicas de espaço e tempo do processo específico que engendrou os planos diretores dessa região.

A análise mais meticulosa desse momento aponta que alguns daqueles os quais detinham os poderes locais estavam ciosos das necessidades sociais candentes, buscando, fundamentalmente, em paralelo à elaboração dos planos diretores, ampliar emprego e renda em seus municípios. Conhecedores do potencial do setor imobiliário como gerador de empregos para a parcela da população sem qualificação para ocupação em setores de alta tecnologia, os responsáveis pelas administrações municipais posicionaram-se mais "fraternalmente" que o necessário em relação aos empreendedores imobiliários, sendo mais permissivos com as interferências desses agentes no desenho adequado dos espaços públicos, pois pretendiam atrair investimentos, priorizando emprego e renda no curto prazo, em detrimento das promessas futuras vinculadas à implantação dos planos elaborados.

Por outro lado, em âmbito federal, a Câmara dos Deputados buscava facilitar as ações do capital imobiliário, discutindo a substituição da Lei n. 6.766/1979, que tratava do parcelamento do solo urbano e subseqüentes, notadamente no que se refere à infra-estrutura e aos espaços livres e institucionais. Tal processo se tornou mais evidente com o lançamento do Programa de Aceleração do Crescimento - PAC, pelo Executivo Federal, em 28 de janeiro de 2007, englobando políticas de crescimento que priorizaram cinco blocos dentre os quais habitação, saneamento e transportes de massa, privilegiando, especialmente, a infra-estrutura, as rodovias e portos, visando incrementar os investimentos privados.

Constatadas essas ações facilitadoras ao capital imobiliário privado como cenário econômico da gestão pública, convém apontar, aqui, a grande contradição que a simples comparação entre o Estatuto da Cidade e a recém-desvelada forma de urbanização dispersa e fragmentada apresenta, fazendo saltar à vista a resignificação do vazio urbano como fenômeno espacial. 
Sabe-se que o Estatuto começou a tramitar pelo Projeto de Lei n. 181/1989, de autoria do senador Pompeu de Sousa, e continuou tramitando por 12 anos consecutivos no Congresso Nacional, tendo sido promulgado sob a Lei n. 10.257/2001. Esta lei, essencialmente, regulamenta os artigos 182 e 183 da Constituição Federal aprovada em 1988 e faz do plano diretor o instrumento básico da política de desenvolvimento urbano.

artigo 182 da Constituição Federal dispõe, em seu parágrafo 4을

"§4으 - É facultado ao Poder Público municipal, perante lei específica para área incluída no plano diretor, exigir nos temos da lei federal, do proprietário do solo urbano não edificado, subutilizado ou não utilizado, que promova seu adequado aproveitamento, sob pena, sucessivamente, de:parcelamento ou edificação compulsórios;imposto sobre a propriedade predial e territorial urbana progressiva no tempo;desapropriação com pagamento mediante títulos da dívida pública...".

Portanto, evidencia-se que os espaços livres públicos, no âmbito da legislação federal, não foram equacionados adequadamente do ponto de vista da construção da qualidade do espaço urbano e da esfera de vida pública. Foram pensados apenas como ausência de espaços edificados, a serem eliminados, já que, pela não-utilização, encarecem e prejudicam a livre passagem de toda a infra-estrutura urbana.

Como tratar os vazios urbanos como obstáculos à função social da propriedade, conforme dispõe o Estatuto da Cidade, quando se constata que essa nova forma de urbanização - fragmentada e dispersa - foi desenhada simultaneamente ao nascimento da denominada megalópole do Sudeste do Brasil? Qual sua escala de aplicação? Qual órgão gestor deve aplicá-la? Como aproveitar grandes áreas "desocupadas" para preservar valores naturais e culturais, visando garantir qualidade de vida nas cidades circunvizinhas?

Os grandes espaços livres existentes nos interstícios das malhas urbanas, entre as inúmeras cidades que compõem o complexo megapolitano do Sudeste brasileiro, surgiram para preservar matas, mananciais, serras e outros acidentes geográficos ao redor das grandes aglomerações como São Paulo e Rio de Janeiro. Entre as cidades de menor porte, as áreas livres mais recorrentes são constituídas por reservas de terra passíveis de subdivisão ou áreas de preservação como APAs, segmentos de florestas nativas, paisagens notáveis, etc. Sem esses espaços livres seria praticamente impossível manter a vida nas aglomerações urbanas, especialmente em relação à demanda de água e à qualidade e temperatura do ar. $\bigcirc$ complexo da serra do Japi, em Jundiaí, no estado de São Paulo, é paradigmático: mantém flora e fauna nativas, oferece água potável, é fator decisivo no controle da qualidade e temperatura do ar e ainda permite algum uso urbano, especialmente habitacional de baixa densidade, turismo e lazer.

Fica evidente que, com o caráter disperso e fragmentado da malha urbana, é preciso decidir a aplicação da função social da propriedade em vazios urbanos, em escalas adequadas com cada cidade, de acordo com a necessidade das áreas livres constituintes das esferas de vida pública, compatíveis às necessidades da comunidade, porém sem 
perder a visão do todo espacial produzido pela megalópole. É preciso pensar o espaço, algumas vezes, extrapolando os limites municipais, elaborar políticas de impostos compatíveis e valorativas com a preservação paisagística, estudar as diferentes escalas e naturezas da malha urbana e seu entorno. Dessa forma, torna-se possível revalorizar as áreas públicas e paisagens de uso coletivo, superando a relação mecânica, evitando que áreas de grande valor paisagístico-cultural sejam destruídas apenas para eliminar vazios urbanos, como se o vazio fosse parte indissociável do espaço construído.

Parece que este momento requer pensar-se a qualidade do espaço construído por seu avesso, ou seja, pelo vazio, agora não mais entendido como obstáculo ao barateamento da infra-estrutura urbana, mas como algo a compor a qualidade de vida no espaço em sua esfera pública.

\section{Bibliografia}

QUEIROGA, E. F. A metrópole de Campinas diante da megalópole do Sudeste do Brasil. In: SOUZA, Maria Adélia Aparecida de (Org.). A metrópole e o futuro. Campinas: Edições Territorial, 2008.

QUEIROGA, E. F. ; BENFATTI, Denio Munia. Entre o nó e a rede, dialéticas espaciais contemporâneas: $\bigcirc$ caso da metrópole de Campinas diante da megalópole do Sudeste do Brasil. Revista Brasileira de Estudos Urbanos e Regionais (ANPUR), Rio de Janeiro, v. 9, p. 41-52, 2007.

SOUZA, Maria Adélia. Cidades médias e desenvolvimento industrial - Uma proposta de descentralização metropolitana. São Paulo: Secretaria de Economia e Planejamento do Estado de São Paulo, 1978.

PORTAS, Nuno. Tendências do urbanismo na Europa. Revista Óculum, Campinas: PUCCamp, n. 3, 1992. 
